\title{
Method of heterogeneous information resources structuring and systematizing for Internet portals development
}

\author{
L. Globa ${ }^{\# 1}$, R. Novogrudska ${ }^{\# 2}$, O. Oriekhov ${ }^{* 3}$ \\ \# National Technical University of Ukraine "Kyiv Polytechnic Institute" \\ Peremohy av., 37, Kyiv, Ukraine Address Including Country Name \\ 1 lgloba@its. kpi.ua \\ 2 Rinan@ukr.net \\ * EPAM Systems \\ Kudrashova str., 14-6, Kyiv, Ukraine \\ 2 oleksandr_oriekhoveepam.com
}

\begin{abstract}
The article presents the method of heterogeneous information available on portal structuring and systematizing. Such kind of method operates with the original general model that integrates model of portal knowledge representation, model of portal business processes and methods of informational and computational recourses collaboration. It is in proposed to develop specific method of heterogeneous information resources structuring and systematizing while designing knowledge Internet portals in appropriate subject field. Such method is devoted to the next task solving: qualitative knowledge representation; information systematization and structuring; formalization of knowledge based on mathematical models (for chosen subject field); content-based search.

Keywords: Internet portal, knowledge representation, business process, ontology, information systematization, functional elements, knowledge representation
\end{abstract}

\section{INTRODUCTION}

Nowadays there is wide variety of technical resources and software of different types for various engineering tasks solutions. But their usage is sometimes restricted. It is due to two factors: software and technical recourses of such type are very expensive or too hidden for commercial purposes. Besides new theoretical and practical results obtained by the researchers in specialized numerous institutions are usually concentrated in the very institutions and their usage elsewhere is limited. Thus providing the access to the information for as many users as possible today is actually becoming a real challenge.

From the other side big amounts of information already stored in the Internet are rather poorly structured and systematized. Moreover they are distributed through different Internet sites, electronic libraries and archives. This prevents quick and easy access to specific knowledge in definite technical and scientific spheres.

The portal contains not only static, but also dynamic information obtained from the processing of large amounts of data. Thus, the portals can not only include certain static data objects, but some software tools to provide new information. Such tools may be relevant for

- the foreseeing economic development on enterprise businesses portals of any enterprise,

- producing means of high technology and performing necessary calculation tasks on portals in engineering activity,

- generating new knowledge while using portals in science.

Thus such portals could be considered as specialized portals of intellectual knowledge that operate information resources, as well as some functional resources responsible for new knowledge generation by processing the information available.

The development of information technology and modern enterprise distributed systems widely use software technologies that allow to receive some generalized information and to make conclusions based on a large amount of corporate information. They include the corporate governance system used in different ministries and departments. In this case the information is collected on the lower levels of the system and is aggregated at the upper levels and only then different foreseeing and trends, etc. are made. For the construction of such systems databases and knowledge bases technology, data storage descriptions methods and techniques of project management are widely used. But those technologies are not fully adapted to the construction of specialized knowledge portals because of the large heterogeneity and information resources used weak connectivity.

\section{STATE OF THE ART AND BACKGROUND}

In recent years, there are attempts to provide semantic access to information allocated in Internet by means of using ontologies [1] for describing the semantics of Web resources. So, the Semantic Web approach [2] suggests supplying Web resources with annotations in the RDF [3] or OWL [4]. Using such annotations, the intelligent search agents can provide more relevant responses to a user query as compared to traditional search engines. There has been certain progress in this direction; however that does not improve the situation in general, since 
Web resources annotated in such a manner are an infinitesimal drop in the sea of the Web.

The problem how to choose appropriate method and models for portal development was detected in various scientific works $[5,6]$.

Main achievement in this direction was made while developing portal knowledge representation model using ontology. The papers that deal with portal designing based on ontology usually suggest to divide ontology of a portal into some components that are represented as separated ontologies that connects each other by relations of defined type. [7, 8]

However, the issue of how to organize information and computing resources on portals still remain really unexplored. The main tasks that are not realized by approaches to knowledge portal development are:

- The models and methods of portal development and its functioning should be independent from portal domain, while knowledge of the portal depends on subject field it is used for.

- The business processes modeling for portal development should be used like the instrument for obtaining of knowledge or services needed for end user.

- Various approaches to portal development usually do not provide the mechanism of meaningful search methods development

\section{THE METHOD OF HETEROGENEOUS WEAKLY- COUPLED INFORMATION SYSTEMATIZATION}

Thus the urgent task in portal designing is to improve the efficiency of access to information and computing resources by means of heterogeneous weakly coupled information systematization. A few problems appear in analyzing this task:

- qualitative knowledge representation;

- $\quad$ systematization of and structuring of information;

- formalization of knowledge based on mathematical models (for chosen subject field);

- a content-based search;

It is possible to select two types of objects on the portal:

Information elements - static objects not carrying a functional sense. They do not deal with a process and do not contain sequences of actions.

Functional elements - dynamically changing elements that represent the process by themselves.

To solve the problems mentioned it is in need to develop specific method of heterogeneous information structuring and systematizing while designing knowledge Internet portals in appropriate subject field [9]. It is proposed to design such method devising two models and one method drafting (Fig. 1):

knowledge representation model that will form description structures for informational and functional elements of the portal [10],

business process model that allows to describe collaboration of such elements [11],

method of dynamic knowledge generation operates notions defined in two above mentioned models.

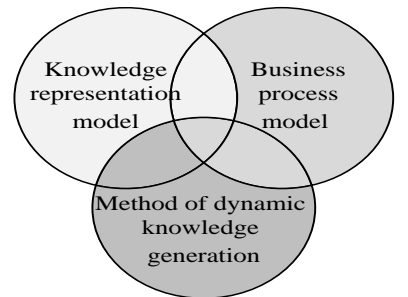

Fig. 1. Components of heterogeneous information structuring and systematizing method

The following achievements will be available due to the implementation of the approach proposed:

Development of the method for heterogeneous weakly coupled information systematization and structuring using original model as well as dynamic knowledge generation method based on this model.

Qualitative knowledge representation on the portal by specific models of knowledge representation development.

Description of portal informational and functional element collaboration by business process models designing.

Organization of meaningful search through the portal space using formalized method of search that allows to set search request in terms of subject area.

\section{KNOWLEDGE REPRESENTATION MODEL}

It is proposed to use the ontology model as portal knowledge representation model. So the portal ontology model development will be provided [12]. Information structuring and arranging on the portal is organized in a friendly way for the end user implementing problem-oriented navigation tools. Information search based on the formal structures set in ontology model is organized in such a way that end-user can specify the request not only by keywords, but what is more in familiar terms of subject field.

Formal description of ontology may be specified as $\mathrm{O}=\{\mathrm{C}$, $\mathrm{A}, \mathrm{R}, \mathrm{T}, \mathrm{F}, \mathrm{D}\}$, where $\mathrm{C}$ is the set of classes that describes the notions of a subject field; $A$ is the set of attributes that describes the features of notions and relations; $\mathrm{R}$ is the set of relations specified for classes: $R=\left\{R_{A S}, R_{I A}, R_{n}, R_{C D}\right\}$,where $R_{A S}$ is associative relation, $R_{I A}$ is relation "is-are", $R_{n}$ is relation of "heredity", $R_{C D}$ is relation "class-data"; $\mathrm{T}$ is the set of standard types of attributes values; $F$ is the set of limits for values of attributes notions and relations; $\mathrm{D}$ is the set of class exemplar [13].

Let us take a look at the example of ontology model for knowledge portal in the field of strength of materials development. First it is in need to divide general ontology into some components (specific ontologies), then to describe the elements of each specific ontology and finaly to draw up formal description structures to each element of ontology model [14].

It is proposed to divide general engineering ontology of the portal in the field of strength of materials into three ontologies [15]: engineering activity ontology, engineering knowledge ontology and engineering computations ontology (Fig. 2): 
Engineering activity ontology (EAO) includes general classes of notions related to the organization of scientific activities.

Engineering knowledge ontology (EKO) includes the metanotions that specify structures to describe the problem field.

Engineering computations ontology (ECO) unites classes that describe calculation abilities realized at the portal.

\begin{tabular}{|c|c|c|}
\hline & Engineering ontology & \\
\hline $\begin{array}{l}\text { Engineering } \\
\text { activity ontology }\end{array}$ & $\begin{array}{l}\text { Engineering } \\
\text { knowledge } \\
\text { ontology }\end{array}$ & $\begin{array}{l}\text { Engineering } \\
\text { computations } \\
\text { ontology }\end{array}$ \\
\hline
\end{tabular}

Fig. 2. Components of general portal ontology

Besides three ontologies described it is proposed to involve one more component - Subject field ontology into portal knowledge representation model. Subject field ontology (SFO) represents general knowledge of subject field, such as hierarchy of notions classes and their semantic relations. The ontology of subject field describes the science of strength of materials as a whole as well as its parts, notions and their connections. Metanotion of EKO are realized into these notions and they can form the hierarchy using "is-are" relation.

By way of the example let us consider the elements of EKO as well as on their formal description [16]. We should list all elements of the ontology mentioned above: classes, attributes, relations of four types specified for ontology classes, data of the class.

This are some classes of EKO:

The method of investigation - $C_{1}\left(O_{3}\right)$. This class is used to describe the methods used in engineering research. Attributes of this class are the name of the method and its author. $C_{1}\left(O_{3}\right)=\left(\mathrm{A}_{\mathrm{C}_{1}}, D_{C_{1}}\right)$

The object of study - $\mathrm{C}_{2}\left(\mathrm{O}_{3}\right)$. The concepts of this class define objects of study and structures to describe them. Attributes include the name of the object and its parameters (characteristics). $C_{2}\left(O_{3}\right)=\left(\mathrm{A}_{\mathrm{C}_{2}}, D_{\mathrm{C}_{2}}\right)$

The result of the study - $\mathrm{C}_{3}\left(\mathrm{O}_{3}\right)$. Data concentrated in this class are used to describe the results of scientific activities and their typification. The class contains the result of the researches that are already obtained by the scientists. The results of these researches are usually reflected in numerous publications. Attributes include the name of the class, the author of the research and required characteristics. $C_{3}\left(O_{3}\right)=\left(\mathrm{A}_{\mathrm{C}_{3}}, D_{C_{3}}\right)$.

The aim of the study - $\mathrm{C}_{4}\left(\mathrm{O}_{3}\right)$. The concepts described in this class reflect the purpose of the study and the challenges to be addressed. Attributes of the class is the direction of research. $C_{4}\left(O_{3}\right)=\left(\mathrm{A}_{\mathrm{C}_{4}}, D_{C_{4}}\right)$.

Research equipment - $\mathrm{C}_{5}\left(\mathrm{O}_{3}\right)$.The concepts in this class describe the equipment that is used to conduct the study. Attributes include type of equipment, name, year, size, some required experiment parameters and characteristics. $C_{5}\left(O_{3}\right)=\left(\mathrm{A}_{\mathrm{C}_{5}}, D_{C_{5}}\right)$

Branch of science - $\mathrm{C}_{6}\left(\mathrm{O}_{3}\right)$. This class allows you to structure scientific or engineering science and to allocate its important sections and subsections. The concepts in this class describe different areas of research on the basis of data collected. Attributes of the class are science section and the direction of research. $C_{6}\left(O_{3}\right)=\left(\mathrm{A}_{\mathrm{C}_{6}}, D_{C_{6}}\right)$.

There are some relations for EKO.

Associative relations - $R_{A S}\left(O_{1}\right)=\left\{C_{i}\left(O_{1}\right) \times C_{j}\left(O_{1}\right)\right\}$.

"Applies to" - relates the method and type of research facilities to which it is applied. $R_{A S_{3}}=\left\{C_{1}\left(O_{3}\right) \times C_{2}\left(O_{3}\right)\right\}$

"Carried on" - links the research method with research equipment. $R_{\mathrm{AS}_{4}}=\left\{\left(\mathrm{C}_{1}\left(\mathrm{O}_{3}\right) \times \mathrm{C}_{5}\left(\mathrm{O}_{3}\right)\right)\right\}$.

"Aimed at" - the appointment of research associates research method. $R_{A S_{5}}=\left\{C_{4}\left(O_{3}\right) \times C_{1}\left(O_{3}\right)\right\}$.

"Received on" - the result of research links with research equipment, which it was received. $R_{A S_{6}}=\left\{C_{3}\left(O_{3}\right) \times C_{5}\left(O_{3}\right)\right\}$

"Conducted with" - the result of the study relates to the object of research. $R_{A S_{7}}=\left\{C_{3}\left(O_{3}\right) \times C_{2}\left(O_{3}\right)\right\}$.

"Uses" - relates to the branch of science method of science research. $R_{A S_{8}}=\left\{C_{6}\left(O_{3}\right) \times C_{1}\left(O_{3}\right)\right\}, R_{A S_{9}}=\left\{C_{6}\left(O_{3}\right) \times C_{3}\left(O_{3}\right)\right\}$, $R_{A S_{8}}=\left\{C_{6}\left(O_{3}\right) \times C_{5}\left(O_{3}\right)\right\}$.

"Investigates" - a branch of science relates to the object and purpose of the research study. $R_{A S_{12}}=\left\{C_{6}\left(O_{3}\right) \times C_{2}\left(O_{3}\right)\right\}$, $R_{A S_{11}}=\left\{C_{6}\left(O_{3}\right) \times C_{4}\left(O_{3}\right)\right\}$

Relation "is-are" - $R_{I A}\left(O_{1}\right)=C_{k}\left(O_{1}\right) \subset C_{m}\left(O_{1}\right)$ :

The ratio of "is-are" is the relationship between class research equipment and facilities for carrying out different types of experiments, the measuring equipment. $C_{5} \subset C_{5_{1}} \wedge C_{5_{2}} \wedge C_{5_{3}} \wedge C_{5_{4}}$.

Inheritance relationship - $\mathrm{R}_{\mathrm{n}}\left(O_{1}\right)=\mathrm{a}_{\mathrm{i}}, \mathrm{r}_{\mathrm{i}}\left|\mathrm{A}_{\mathrm{C}_{\mathrm{m}}}\left(O_{1}\right) \rightarrow \mathrm{a}_{\mathrm{i}}, \mathrm{r}_{\mathrm{i}}\right| \mathrm{A}_{\mathrm{C}_{k}}\left(O_{1}\right)$ :

Relation of inheritance is used for class research equipment and its subclasses are set for different types of experiments, the measuring equipment. $\mathrm{A}\left(\mathrm{C}_{5}\right), \mathrm{R}\left(\mathrm{C}_{5}\right) \rightarrow \mathrm{A}\left(\mathrm{C}_{5_{1}}\right), \mathrm{R}\left(\mathrm{C}_{5_{1}}\right)$ $\mathrm{A}\left(\mathrm{C}_{5}\right), \mathrm{R}\left(\mathrm{C}_{5}\right) \rightarrow \mathrm{A}\left(\mathrm{C}_{5_{2}}\right), \mathrm{R}\left(\mathrm{C}_{5_{2}}\right)$

$$
\mathrm{A}\left(\mathrm{C}_{5}\right), \mathrm{R}\left(\mathrm{C}_{5}\right) \rightarrow \mathrm{A}\left(\mathrm{C}_{5_{3}}\right), \mathrm{R}\left(\mathrm{C}_{5_{3}}\right), \mathrm{A}\left(\mathrm{C}_{5}\right), \mathrm{R}\left(\mathrm{C}_{5}\right) \rightarrow \mathrm{A}\left(\mathrm{C}_{5_{4}}\right), \mathrm{R}\left(\mathrm{C}_{5_{4}}\right) .
$$

Relation class-data - $R_{C D}\left(O_{1}\right)=C_{j}\left(O_{1}\right) \subseteq D_{i}\left(O_{1}\right)$

Such type of relation is used for all classes of this ontology. $C_{1}\left(O_{3}\right) \subseteq D, \quad A_{C_{1}} \subseteq A_{D} \quad, \quad C_{2}\left(O_{3}\right) \subseteq D, A_{C_{2}} \subseteq A_{D}$
$C_{3}\left(O_{3}\right) \subseteq D, A_{C_{3}} \subseteq A_{D}, C_{4}\left(O_{2}\right) \subseteq D, A_{C_{4}} \subseteq A_{D}, C_{5}\left(O_{3}\right) \subseteq D, A_{C_{5}} \subseteq A_{D}$.

Figure 3 shows classes and relations of EKO. 


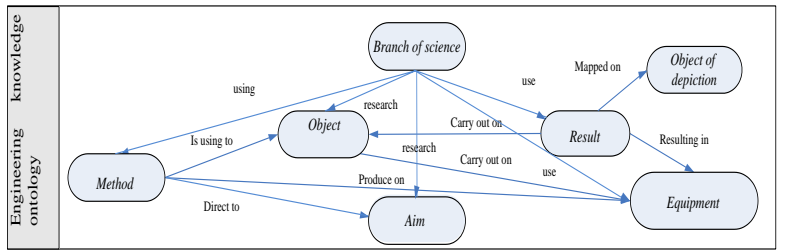

Fig. 3. Elements of engineering knowledge ontology

Ontology notions defined in the model of knowledge representation are used in the method of dynamic knowledge generation.

\section{PORTAL BUSINESS PROCESS MODEL}

As the result of using of business process models it becomes possible to determine the interaction, collaboration and sequence of data and services, information and computing resources, databases and knowledge bases of portal [17]. One of the most important requirements is to identify the sequence of the operations to be initialized by different demands of portal users' activation. It is also in needed to define in appropriate way the mechanism of informational and computational recourses coherence.

One of the most important issues is to identify the sequence of operation initialized on different users request execution. Proper definition of sequence allow to:

- to improve the quality of computational tasks performance (search of data and services for different computational tasks realization),

- to raise the effectiveness of information search,

- to maximize speed of different portal components coherence.

While constructing the business process models for the Internet portal in the field of strength of materials it is possible to understand the collaboration and cooperation of data and services used in different search requests and calculation tasks realized on the portal [18].

Due to the appropriate definition of sequence while modeling the portal business processes the following advantages are obtained:

- It is easy to observe the life cycle of each object.

- It is clear to understand what call (message) is sent by what object and which object is addressed to.

- The sequence of calls that follow each other is clearly shown.

- It is possible to present visually the sequence of actions when portal is function.

As an example of portal business process modeling it is proposed to examine business process models for portal in the field of strength of materials developed according to the UML notation (Fig. 4, Fig 5, Fig. 6) [19].

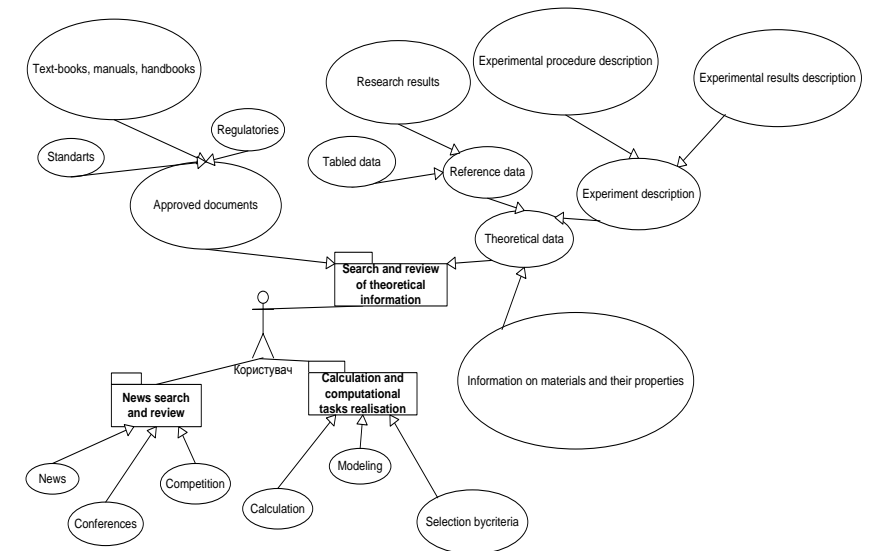

Fig. 4. Use case diagram of portal processes

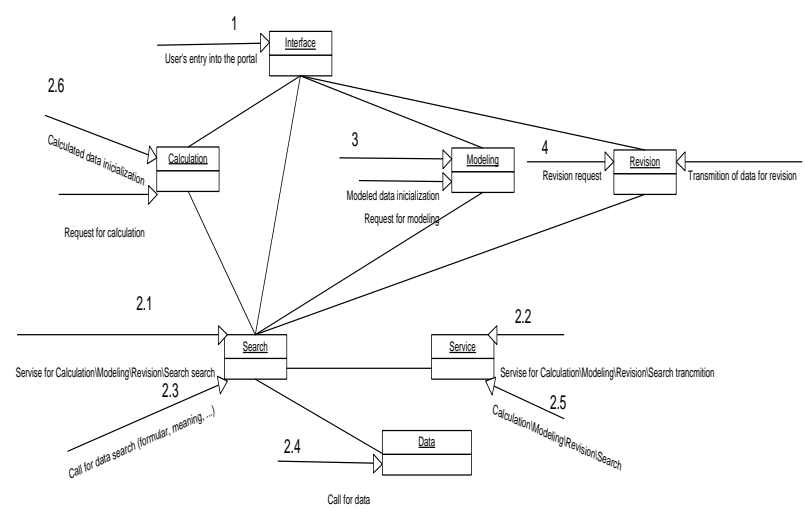

Fig. 5. Communication diagram of portal processes

Portal functionality from the point of view of business processes modeling is fully described by means of Use case diagram. While coherence and sequence of different portal components initialization is specified with the help of cooperation and sequence diagrams of UML notation.

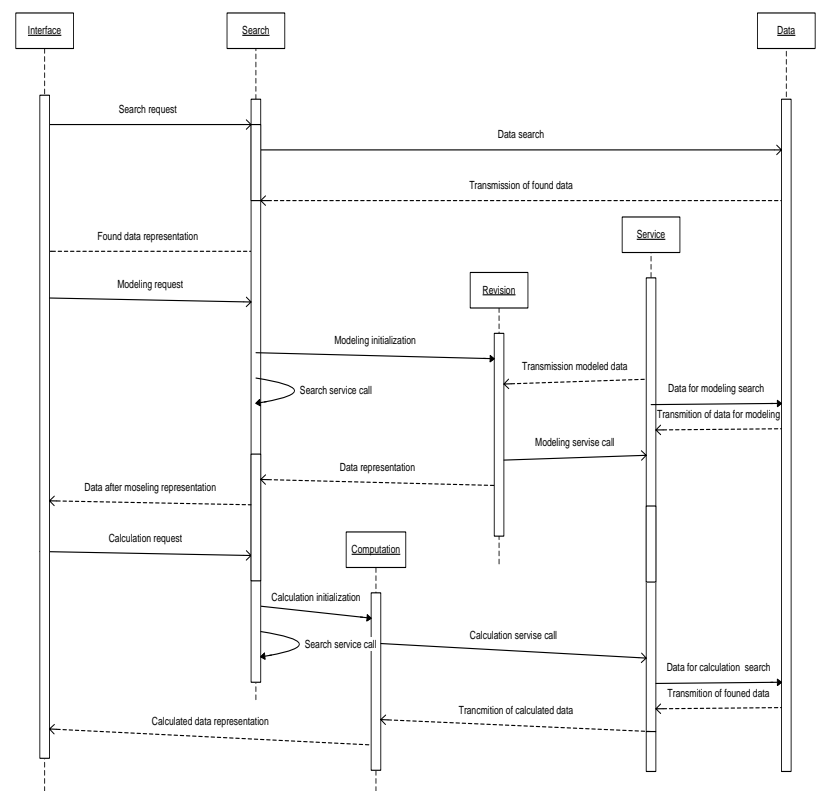

Fig. 6. Sequence diagram of portal processes 
The following main business processes were identified while analyzing process occurring on the portal in the field of strength of materials:

BP_1 - Calculation tasks;

BP_2 - Building (charts, graphs and dependencies);

BP_3 - Simulation (Modeling of construction sustainability depending on material selected, modeling of material according material dependency);

BP_4 - Selection of material in accordance with specific criteria;

BP_5 - The choice of construction based on user-defined characteristics;

BP_6 - Calculation according to formulas of the necessary data set by the user;

BP_7 - Preview (of theoretical information, practical results, information on events related to this subject area);

BP_8 - Search.

The business processes that take place on the Internet portal of knowledge during of its life cycle were analyzed. Due to its main functions allocation mathematical model was developed. It allows to understand and define the relationship and cooperation of data and services that are used in search queries and computing tasks implemented on the portal. Sets have been allocated that correspond to the information division on blocks allocated in accordance with the substantive value of the information and operations with it.

Model of portal business process can be provided by the following formalism:

$$
\mu=\left(\mathrm{O}, \mathrm{P}, \mathrm{E}_{\mathrm{c}}\right)
$$

where:

$$
\begin{aligned}
& \mathrm{O} \text { - Object; } \\
& \mathrm{P} \text { - Depending; } \\
& \mathrm{E}_{\mathrm{c}} \text { - Context-dependent elements. }
\end{aligned}
$$

As the objects of portal business process can separate processes and static elements, it is important to take account of this feature in order to describe models of business processes. Thus, the general processes that take place on portal while its functioning can be represented as:

$$
\mathrm{O}=\{\mathrm{Of}\} \mathrm{U}\{\mathrm{Onf}\}
$$

$\mathrm{O}$ - is the set of 2 subsets union: functional and non-functional objects.

The set of non-functional objects is $\{$ OnfId, $\mathrm{Id}=1,3\}$,

$$
\text { Onf1 = I - Interface, }
$$

Onf2 $=$ D - Data,

$$
\text { Onf3 }=\mathrm{S}-\text { Service }
$$

The set of functional objects is $\{\mathrm{OfId}, \mathrm{Id}=1,4\}$,

$$
\begin{aligned}
& \text { Of1 }=\mathrm{C}-\text { Calculation, } \\
& \text { Of2 }=\mathrm{B}-\text { Modeling, } \\
& \text { Of3 }=\mathrm{R}-\text { Browsing, } \\
& \text { Of4 }=\mathrm{F}-\text { Search }
\end{aligned}
$$

Set of dependencies of portal business process is a set of nine parameters $\{\mathrm{P}(\mathrm{V}) \mathrm{Id}, \mathrm{Id}=1,9\}$, divided into groups depending on the variable for which the option is used \{VId, $\mathrm{Id}=1,4\}$ :

Parameters:
$\mathrm{P}(\mathrm{V}) 1$ User Login to the portal

$\mathrm{P}(\mathrm{V}) 2$ Request on $\mathrm{Vi}, \mathrm{i}=1,3$

$\mathrm{P}(\mathrm{V}) 3$ Service call for $\mathrm{Vi}, \mathrm{i}=1,4$

$\mathrm{P}(\mathrm{V}) 4$ Realization of $\mathrm{Vi}, \mathrm{i}=1,4$

$\mathrm{P}(\mathrm{V}) 5$ Call for V4

$\mathrm{P}(\mathrm{V}) 6$ Implementation of V4

$P(V) 7$ Service transfer Vi, $i=1,4$

$\mathrm{P}(\mathrm{V}) 8$ Information initialization after $\mathrm{P}(\mathrm{V}) 4, \mathrm{P}(\mathrm{V}) 6$

$\mathrm{P}(\mathrm{V}) 9$ Return of rewiring information

Variablese:

$\mathrm{V} 1$ = Computational

$\mathrm{V} 2=$ Modeling

$\mathrm{V} 3=$ Rewiring

V4 = Search

The set of context-dependent elements is a set of parameters $\left\{E_{c} I d, I d=1, n\right\}$. Elements of this set are directly dependent on subject aria of developed portal and are used for the description of context-dependent blocs of information that are being integrated into portal subject aria. So, we can conclude that:

$\mathrm{E}_{\mathrm{c}}=\mathrm{A}-$ is an informational union.

\section{METHOD OF DYNAMIC KNOWLEDGE GENERATION}

The method of dynamic knowledge generation operates with notions defined in the model of knowledge representation and business process model. Using such a method it becomes possible to organize the meaningful search through the portal space utilizing formalized terms of subject area set by the user in the search request. This method consists of four steps (Fig. 7).

Presented here is the description of each step of dynamic knowledge generation method:

Stage 1: Description of the terms (phrases) set by the user in the search request by means of elements specified in the ontology model.

Stage 2: Representation of the ontology model terms set in the stage 1 by formal structures.

Stage 3: Search of the term relevant to terms determined in stage 2, search is carried out based on semantic scheme of the ontology model.

Stage 4: Presentation of the search result. The result can be depicted in notions familiar to the user; so, the term found on the stage 3 should be transferred from formal structure to the notion of the ontology model, then at last it has to be transformed to the concept of the natural language for the user to understand. 


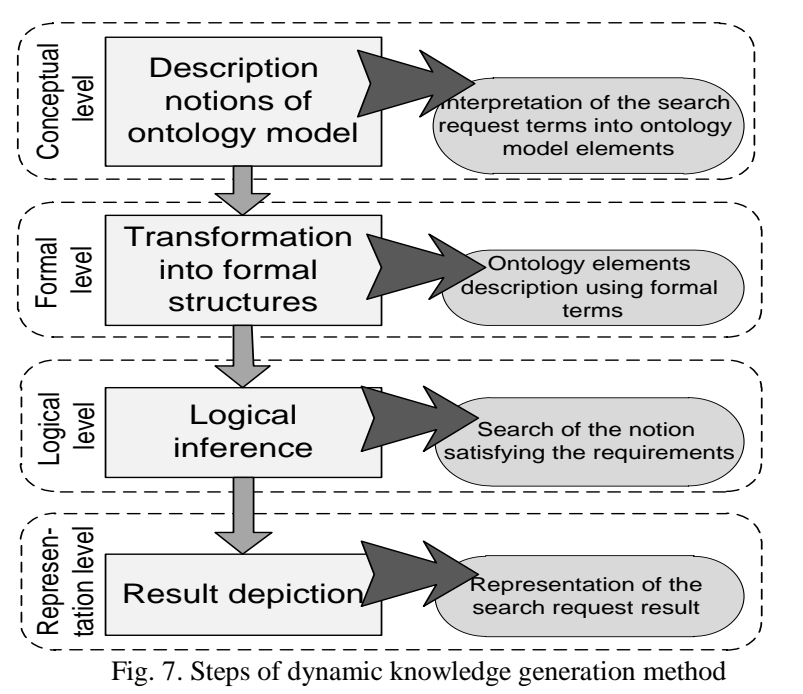

Each step of dynamic knowledge generation method can be correlated with certain representation level.

1 stage - Conceptual level - presentation of knowledge by concepts,

2 stage - Formal level - formalization of concepts using formal theories,

3 stage - Logical level - logical inference, organization of search process based on mathematical formulas,

4 stage - Representation level -presentation of the result using natural language elements.

It is very important for the user to set the search request not only with the help of keywords, but with the help of wellknown terms of subject field the user is a specialist at. Search request organized by means of the ontology is simple for the user [20].

Let us explore the process of dynamic knowledge generation based on the following example of the search request: "To find the results of research, that was held with steel, received by Gain V.A. in 2008 and that are described in the book "Steel behavior", published by the German Institute of Material Science" [21].

Stage $1+$ Stage 2

In the first stage the terms of search request should be transferred into the terms of the ontology model, the second stage requires to convert terms of the ontology model into formalisms:

Class: "Research result", $C_{1}$

Relation: "Was held with" - $R_{A S_{1}}$

Class: "Research object" - $C_{2}$

Attribute: "Name" - $\mathrm{A}_{\mathrm{C}_{2}}$

Class exemplar: "Steel" - $D_{\mathrm{C}_{2}}$

Relation: "Received" - $R_{A S_{2}}$

Class: "Person" - $C_{3}$

Attribute: "First name, Last name, Surname" - $A_{\mathrm{C}_{3_{1}}}$
Class exemplar: "Gain V.A." - $D_{\mathrm{C}_{3_{1}}}$

\&

Class: "Research result" - $C_{1}$

Attribute: "Year" - $A_{c_{32}}$

Class exemplar: "2008”, $-D_{\mathrm{C}_{3_{2}}}$

Relation: "Described" - $R_{A S_{3}}$

Class: "Literature", $C_{4}$

Relation: "is-are" - $R_{I A_{45}}$

Class: "Teaching materials" - $C_{5}$

Attribute: "Name" - $\mathrm{A}_{\mathrm{C}_{5}}$

Class exemplar: "Steel behavior" - $D_{\mathrm{C}_{5}}$

Relation: "Published" - $R_{A S_{4}}$

Class: "Organization" $-C_{6}$

Attribute: "Name" - $\mathrm{A}_{\mathrm{C}_{6}}$

Class exemplar: "German Institute of Material Science" - $D_{\mathrm{C}_{6}}$

For search request realization such description of classes and relations are actual:

- classes:

$$
\begin{aligned}
& C_{2}\left(\mathrm{~A}_{\mathrm{C}_{2}}, D_{C_{2}}, R_{C_{2}}\right), \\
& C_{3}\left(\mathrm{~A}_{\mathrm{C}_{3}}, D_{C_{3}}, R_{C_{3}}\right), \\
& C_{4}\left(\mathrm{~A}_{\mathrm{C}_{4}}, D_{C_{4}}, R_{C_{4}}\right), \\
& C_{5}\left(\mathrm{~A}_{\mathrm{C}_{5}}, D_{C_{5}}, R_{C_{5}}\right), \\
& C_{6}\left(\mathrm{~A}_{\mathrm{C}_{6}}, D_{C_{6}}, R_{C_{6}}\right),
\end{aligned}
$$

- relation of "is-are" type:

$$
R_{I A_{45}} \leftarrow C_{4} \subset C_{5}
$$

- associative relations:

$$
\begin{aligned}
& R_{A S_{1}}=\left\{C_{1} \times C_{2}\right\}, \\
& R_{A S_{2}}=\left\{C_{1} \times C_{3}\right\}, \\
& R_{A S_{3}}=\left\{C_{1} \times C_{4}\right\}, \\
& R_{A S_{4}}=\left\{C_{5} \times C_{6}\right\} .
\end{aligned}
$$

Stage 3

Using formal description given above search request can be presented in such a way on the logical level (stage 3):

$$
\begin{aligned}
& C_{1} \text { f- research result } \\
& \stackrel{R_{A S_{1}} \longrightarrow}{\longrightarrow} D_{\mathrm{C}_{2}} \text { - held with steel } \\
& \stackrel{R_{A S_{2}}}{\longrightarrow} \mathrm{D}_{\mathrm{C}_{3_{1}}} \& \mathrm{D}_{\mathrm{C}_{3_{2}} \text { - received by Gain V.A. in } 2008}
\end{aligned}
$$


$\stackrel{R_{A S_{3}}}{\longrightarrow} D_{\mathrm{C}_{5}} \stackrel{R_{A S_{4}}}{\longrightarrow} \mathrm{D}_{\mathrm{C}_{6}}$ - described in the book "Steel behavior", published by the German Institute of Material Science"

Description of search process can be given with the help of semantic scheme (Fig. 8). Class and relations exemplars set by the user in the terms of Search request are marked with bold text and bold line. Class "Research result" is connected by appropriate associative relations with classes "Research object", "Literature", "Person" and "Organization". In these classes the exemplars set by the user are found: Steel, Gain, Steel behavior, German Institute of Material Science. In such a way exemplar of class "Research Result" that corresponds to these exemplars could be found. So this exemplar is the Theory of strength.

Stage 4

After the search process is finished it is in need to form the search result in notions common to the user. We can represent this in the following sequence:

\section{Logical notion}

ת

Conceptual notion (Ontology element)

$$
\text { ת }
$$

For described example:

Concept on natural language

$C_{1}=$ Class: "Research result", $D_{C_{1}}=$ Data: "Theory of strength".

From the practical point of view the suggested method implementation to give the possibility to get the most relevant result of a search request. The search process is performed based on the terms of the developed ontology model graph and the search query terms are related by the relationship of the ontological model. So, such approach helps to get the appropriate searching result for the end user.

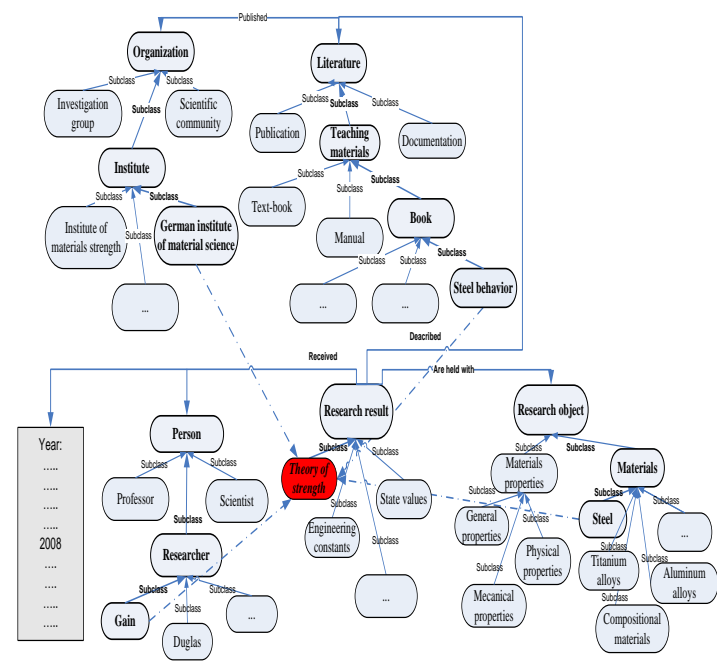

Fig. 8. Search request realization process.

\section{CONCLUSION}

The method of the knowledge Internet portals development is presented in paper. The aim is structuring and systematizing of the heterogeneous information resources available on the portals. The suggested method is based on original model that integrates knowledge representation model, business processes model. For dynamic knowledge generation this model is used.

The ontology model was chosen for description of the portal informational and functional elements, organization of contextrelated search and navigation, formalization and integration of data structures and computational resources. The business process model allows to describe portal informational and functional elements coherence and collaboration, as well as the sequence of data and services interaction. Method of dynamic knowledge generation operates with notions defined in two above mentioned models and enables to generate dynamic answer to the user search request.

Future work will focus on analysis of functional elements of the portal and their correct interaction description on portal. Also we will look through practical implementation of proposed method for two portals development: "Strength of materials portal" and "The portal of National Antarctic Data of Ukraine".

\section{REFERENCES}

[1] Guarino N. Formal Ontology in Information Systems. In N. Guarino (ed.) Formal Ontology in Information Systems. Proceedings of FOIS'98, Trento, Italy, June 6-8, 1998. Amsterdam: IOS Press, 1998. P. 3-15.

[2] Berners-Lee T., Hendler J., Lassila O. The Semantic Web // Scientific American. - 2001. - Vol. 284, N 5, 34-43.

[3] Brickley D., Guha R. RDF Vocabulary Description Language 1.0: RDF Schema W3C Recommendation 10 February 2004. Retrieved from: http://www.w3.org/TR/2004/REC-rdf-schema-20040210/

[4] OWL Web Ontology Language Guide, 2009. Retrieved from ttp://www.w3.org/TR/owl-guide/

[5] Knowledge portals: Ontologies at work, S Staab, A Maedche - AI, magazine, 2001 - aaai.org

[6] Ontological Engineering for Corporate Knowledge Portal Design, TA Gavrilova, VA Gorovoy, Eds. L. Camarinha-Matos, 2003 - books.google.com

[7] A contingent approach on knowledge portal design for R\&D teams: Relative importance of knowledge portal functionalities HJ Lee, JW Kim, J Koh - Expert Systems with Applications, 2009 - Elsevier

[8] How do you evaluate a portal? See for example? V.B. Kreng, C.-Y. Wu / European Journal of Operational Research 176 (2007), p.p.1795-1810

[9] Andrea Jubileu, Henrique Rozenfeld, Creusa Amaral, Janaina Costa and Marcella Costa, "Knowledge Oriented Process Portal for Continually Improving NPD”, pp. 451-460.

[10] Uschold M., Gruninger M. Ontologies: Principles, Methods and Applications // Knowledge Engineering Review11(2), 1996-69 p.

[11] C. Pedrinaci, Domingue, A. Alves de Medeiros. A Core Ontology for Business Process Analysis, Proceedings of the 5th European semantic web conference on The semantic web: research and applications, Springer-Verlag Berlin, Heidelberg, 2008, P. 49-64.

[12] Y. A. Zagogulko, O. I. Borovikova The technology of ontologies constructing for the portals of scientific knowledge // Gornal of NGU: Informational technologies. - 2007. - V. 5, issue 2. - P.12-15.

[13] O. A. Andreeva, O. I. Borovikova, Y. A. Zagogulko,. Archeological knowledge portal: meaningful access to archeological knowledge and informational resources, proceedings of $10^{\text {th }}$ national conference of artificial intelligence “KII'2006”. Moscow, 2006. -V.3, - P.832-840.

[14] John F. Sowa: Knowledge Representation: Logical, Philosophical, and Computational Foundations. Brooks/Cole: New York, 2000

[15] L.S. Globa, I. Mamuzich, R. L. Novogrudska. Development of a model for the internet portal "strength of materials", Materials and technology 46 (2012) 4, pp. 407-410. 
[16] L. S. Globa, R. L. Novogrudskaya Informational resources systematization for the Internet-portal "Strength of materials", Mathematical modeling and Informational technologies, Kharkov, issue 16, № 927, 2011 .

[17] J. Becker. Process Management. A Guide for the Design of Business Processes / J. Becker, M. Kugeler, and M. Rosemann, editors. - Berlin: Springer-Verlag, 2003. -337 p.

[18] A. Sheer. Business-processes. Main notions. Methods, Moscow, MetaTecnology, 2000, p. 182

[19] Grady Booch and James Rumbaugh and Ivar Jacobson, The Unified Modeling Language User Guide, 2 edition, Addison-Wesley, 1998, P. 742
[20] O. I. Borovikova, Y. A. Zagogulko Knovledge portal based on ontology organization, proceedings of international seminar Dialog'2002 "Computing linguistics and intellectual tecnologies". Protvino, 2002. V.2, P.76-82.

[21] L. S. Globa, R. L. Novogrudskaya Integration of informational and computational resources on the portal «Strength of materials», Proceedings of XIth International Conference «The Experience of Designing and Application of CAD Systems in Microelectronics», CADSM 2011, Lviv Polytechnic National University, 2011, p. 162-164 